\title{
Erratum to: An endoscopic modification of the simultaneous 'above and below' approach to large pituitary adenomas
}

\section{Gilberto Ka Kit Leung • Michele Mae Ann Yuen •}

Wing Sun Chow $\cdot$ Philip Yat Hang Tse •

Wai Man Lui

Published online: 24 June 2011

(C) Springer Science+Business Media, LLC 2011

\section{Erratum to: Pituitary}

DOI 10.1007/s11102-011-0319-y

The second author's first name has been erroneously misspelled in the article as "Michelle". It should be "Michele". Correct name is Michele Mae Ann Yuen.

The online version of the original article can be found under doi:10.1007/s11102-011-0319-y.

G. K. K. Leung $(\bowtie) \cdot$ P. Y. H. Tse · W. M. Lui

Division of Neurosurgery, Department of Surgery, Li Ka Shing

Faculty of Medicine, The University of Hong Kong,

Queen Mary Hospital, 102 Pokfulam Road, Hong Kong,

People's Republic of China

e-mail: gilberto@hkucc.hku.hk

\section{M. A. Yuen · W. S. Chow}

Division of Endocrinology and Metabolism,

Department of Medicine, Li Ka Shing Faculty of Medicine,

The University of Hong Kong, Queen Mary Hospital,

Hong Kong, People's Republic of China 